\title{
ADVANCES IN THE EPIDEMIOLOGICAL STUDY OF ORAL-FACIAL DISEASES
}

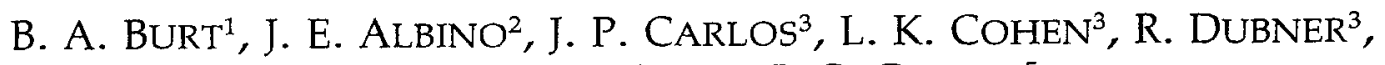 \\ J. A. GERSHEN ${ }^{4}$, AND J. C. GREENE ${ }^{5}$ \\ ${ }^{1}$ The University of Michigan, Ann Arbor, Michigan 48109-2029; ${ }^{2}$ State University of New York at \\ Buffalo, Buffalo, New York 14260; ${ }^{3}$ National Institute of Dental Research, Bethesda, Maryland 20892; \\ ${ }^{4}$ University of California, Los Angeles, California 90024; and ${ }^{5}$ University of California, San Francisco,
} California 94143

Adv Dent Res 3(1):30-41, May, 1989

\section{ABSTRACT}

Both demographic patterns and disease distribution are changing rapidly in the United States. These developments have led to the recognition that the epidemiology of many conditions is poorly understood, and that other research has thus been hindered. Four areas of epidemiological study were chosen for detailed analysis of how new technology will affect the conduct of future research. These areas, selected because information about them will be increasingly needed in an aging society, were periodontitis, temporomandibular disorders (TMD) and other orofacial pain, salivary gland disturbances, and health services research. The potential effect of new technology was examined in the short, intermediate, and long term.

While the nature of epidemiological study is unlikely to change with the advent of new technology, the scope of potential studies will become broader. Advances in diagnostic techniques from elsewhere will permit far more precise diagnosis than is possible at present. Computer technology will permit an efficient system of epidemiological surveillance to provide current data on trends in tooth loss, caries, and periodontitis - data which will complement the results of national surveys. Analytical studies to produce hypotheses on the etiology of oral conditions, especially in such poorly-understood areas as chronic pain and TMD, will help direct clinical research in those areas.

\section{INTRODUCTION}

Epidemiology is the study of the distribution and determinants of health-related states and events in populations, and the application of this study to control of health problems (Last, 1983). In the last 50 or so years, the definition has been broadened from concern only with communicable disease epidemics, in the study of which epidemiology emerged as a recognizable science, to take in all phenomena related to health status. There are four categories of determinants of disease, which are:

(a) Genetic Core: genetic and biological endowment, from broad divisions such as race and gender to the multitude of genetic factors that define human individuality;

(b) Physical Environment: either broad, as in air

A report of the AADR ad hoc Committee on New Frontiers in Oral Health Research

30 quality or living standards, or narrow, such as fluoride in dental plaque;

(c) Social Environment: broad divisions, which include political and economic systems, family organization, cultural mores, health care provisions, work and educational settings; and

(d) Psychosocial Environment: behavior, attitudes, and lifestyles, as they affect beliefs about health and disease and actions on such matters as diet, exercise, and use of tobacco, drugs, and alcohol.

Epidemiology has many uses, such as definition of what is normal and abnormal, discernment of historical trends, description of the natural history of diseases, and the assessment of risk of contracting disease as related to the determinants just outlined. Its most important use, however, is probably in detection of causes in disease etiology (Morris, 1975). Epidemiological analysis seeks associations between disease outcomes and risk factors or suspected etiological agents; cause-and-effect relationships are usually de- 
termined by strength and consistency of associations in a number of studies, as illustrated by the extensive research linking cigarette smoking with lung cancer (Doll and Bradford Hill, 1956, 1964; US Public Health Service, 1975; Breslow, 1980).

Technological developments will influence the future conduct of epidemiological studies, principally by improving methods for diagnosing and quantifying disease and its determinants. The purpose of this paper is to review the current and potential applications of epidemiology in dental research, and to undertake a critical examination of how new technology will affect it in the immediate and longer-term future.

\section{THE NATURE OF RESEARCH}

\section{IN ORAL EPIDEMIOLOGY}

Epidemiology evolved as a science in the great epidemics of the 19th century, when recurring public health crises demanded urgent action at a time of only rudimentary understanding of disease. Development of epidemiology was therefore driven by a public-health imperative. Oral epidemiology, as a branch of the parent discipline, emerged only some generations later with the identification of fluoride in caries prevention (Striffler $e t$ al., 1983). While oral epidemiology is nothing more or less than the application of epidemiological principles and methods to the study of oral conditions, its relative youth has so far restricted it largely to descriptive measurement rather than searches for causes (the fluoride story being a notable exception).

A distinctive feature of oral epidemiology, as practiced to date, is its customary sources of data. The majority of reports in medical epidemiology are based upon analysis of existing data from sources such as vital statistics, disease registries, hospital admissions and discharges, insurance claims, and physicians' records. This is especially true when diseases studied are of low prevalence, where original data collection would be too expensive. By contrast, oral epidemiology has usually relied upon original data collection from clinical examinations carried out by the researchers themselves. This is because the most common oral diseases are highly prevalent, and also because descriptive statistics were necessary to define their distribution prior to more complex applications. Databases, in the sense in which they are utilized in medical epidemiology, have only just begun to be developed for research into the epidemiology of oral conditions. While the roots of oral epidemiology in clinical dentistry should not be lost, the study of lesscommon oral conditions will require greater use of databases where a rich assortment of co-variables permits more precise detection of disease determinants to be achieved. It will also require greater use of analytical techniques from the parent discipline.

\section{Descriptive Studies}

Descriptive epidemiological studies are most useful in monitoring disease trends in a population, where results can be used to plan or evaluate programs and policies for disease control, dentist and auxiliary development, and financing of dental care. The decline in caries among children, for example, was identified by critical comparison of results from a series of descriptive epidemiological studies (Burt, 1978; US Public Health Service, 1981). The current questionwhether periodontal diseases are declining-will in time be answered the same way. Since the patterns of oral diseases strongly influence the practice of dentistry, descriptive epidemiology will clearly continue to fill a fundamental role.

Several well-conducted surveys, beginning in 1960 , have provided national data on oral health. These surveys have been administered by either the $\mathrm{Na}$ tional Center for Health Statistics (NCHS) or by the National Institute of Dental Research (NIDR). The scope of these surveys has been confined largely to caries, periodontal disease, and tooth loss. Fundamental questions on the extent of conditions such as temporomandibular disorders (TMD) and other sources of orofacial pain have not yet been assessed in a national survey, mainly because methods to do so have not been developed.

Economic constraints have dictated that dental data be excluded from some national surveys. They were collected in the first National Health and Nutritional Examination Survey (NHANES I) of 1971-74 (US Public Health Service, 1979), but they were omitted from the NHANES II survey of 1976-80. In addition, shortage of resources at NCHS has resulted in some data taking a long time to be analyzed. These considerations led NIDR to conduct its first national survey, of children aged 5-17, in 1979-80 (US Public Health Service, 1981). NIDR then surveyed adults in 1985-86 (US Public Health Service, 1987), and repeated the survey of children in 1986-87.

Data from national surveys of oral health could be usefully supplemented by results of state-wide and smaller surveys of purposive samples or special groups. The philosophy here is that national surveys of representative samples of population are necessarily complicated and expensive, and therefore cannot be expected to be mounted more frequently than every 5-10 years. In addition, national surveys cannot provide local data, such as for a city or region of a state. If local surveys were carried out to standardized protocols, and optimum use made of electronic data collection, transfer, storage, and analysis, a surveillance system could be set up in which dental data from local surveys could be fed into a national "clearinghouse" and disseminated regularly. The Centers for Disease Control (CDC), which have been conducting disease surveillance of this kind for years, and which already have a dental program (the Dental Disease Prevention Activity), seem the most appro- 


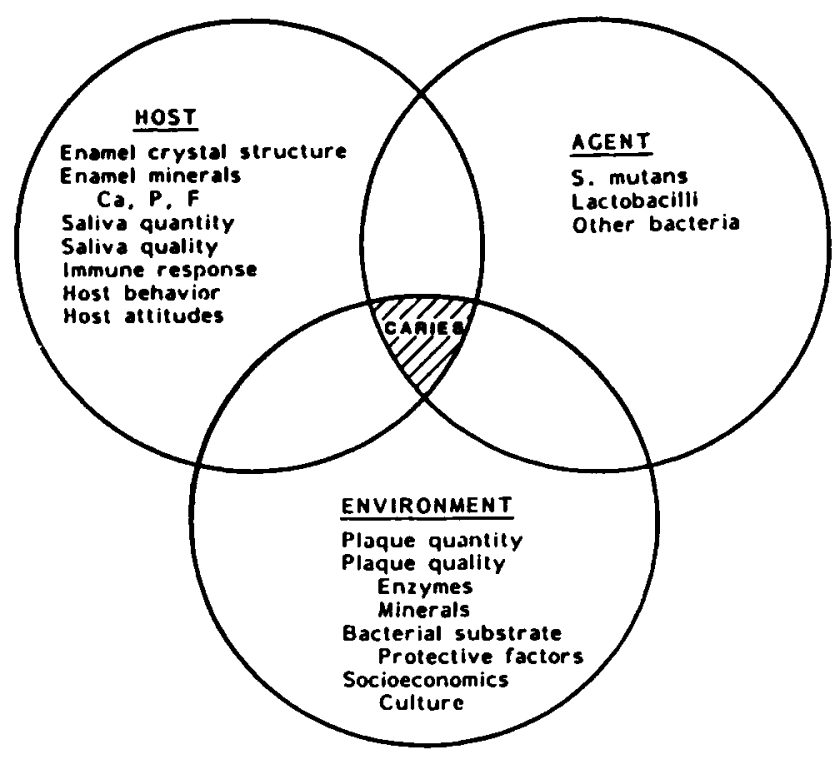

current activities, and collection and transmission of their findings on a systematic basis.

\section{Analytical Studies}

Last (1983) defines an analytical study as an hypothesis-testing method of investigating the association between a given disease or health state or other dependent variable and possible causative factors. Three types of analytical studies are recognized: crosssectional (or prevalence), cohort (prospective or longitudinal), and case-control (retrospective). Although cross-sectional data are usually collected for descriptive reports, oral health data from sources like NCHS national surveys can be related to a variety of other health parameters as well as to factors in the physical, social, or psychosocial environments (Ismail et al., 1984; Chen and Lowenstein, 1984).

Cohort or case-control studies are usually carried out with data from purposive or convenience groups of participants, such as persons in a particular type of employment or in a specific geographic area. Patients in hospitals or dental schools can be studied to test certain hypotheses, though the potential for selection bias with such populations has to be recognized. Analytical studies test hypotheses by measuring the strength of association between a group's disease experience with host factors, environmental measures, or behavioral variables. Where associations are strong and consistent, cause-and-effect can be imputed, but the multifactorial etiology of disease (illustrated for dental caries and periodontal disease in Fig. 1) means that analytical epidemiological studies define necessary causes rather than "prove" etiology (Morris, 1975).

The best-known example of analytical epidemiology in dentistry concerns fluoride. A lengthy and stillcontinuing series of studies began with the early crosssectional observations regarding fluorosis, fluoride content of water, and caries prevalence (Black and McKay, 1916; Dean et al., 1941, 1942), then progressed to the first supplemental water fluoridation studies in the United States and elsewhere. These

Fig. 1-Multifactorial depiction of dental caries and periodontal disease.

priate agency to coordinate these activities. Inherent methodological concerns are recognized, but the benefits to be obtained from such a system are potentially high.

Several state-wide surveys have been held in recent years - for example, in North Carolina in 1976-77 (Hughes et al., 1982), Iowa in 1980 (Beck et al., 1982), and South Carolina in 1982-83 (South Carolina Department of Health and Environmental Control, undated). Other state-wide and smaller local surveys are in process or being planned. A dental surveillance system therefore includes little that is not being done at present. It basically suggests standardization of these gitudinal, although, with the exception of the Netherlands study (Backer Dirks et al., 1961), they were sequential cross-sectional rather than cohort designs in both study and control communities (Arnold et al., 1962; Ast et al., 1962; Blayney and Hill, 1967; Hutton et al., 1956). The next series of studies were the numerous clinical trials for testing other fluoride regimens for caries prevention (Knutson and Armstrong, 1943; Rugg-Gunn et al., 1973; DePaola et al., 1977; Glass and Shiere, 1978).

Analytical study of periodontal disease was hampered for years by the lack of indices for quantifying disease status, which in turn reflected poor understanding of its natural history. Following the development of the first widely-accepted index (Russell, 1956), associations between gingival inflammation and plaque/calculus deposits were identified from cross- 
sectional analytical studies (Russell and Ayers, 1960; Greene, 1963, 1967). Other cross-sectional studies at that time were able to rule out the theory that periodontal diseases were primarily nutritional disorders (Russell, 1963).

Case-control studies - a retrospective design in which a group of persons with the disease in question ("cases") is compared to a group without it ("controls") to measure similarities and contrasts in disease determinants (Schlesselman, 1982)-are rare in oral epidemiology. Classification of persons into those with and without oral diseases has not historically been used much in high-prevalence populations; summary indices of the common oral diseases characteristically measure intensity rather than prevalence. It is uncertain whether characterization of persons with "less" or "more" disease, rather than the usual classification of those "with disease" or "without disease", is a valid design for case-control studies. The relative lack of databases in dental research, mentioned previously, has also hampered the use of case-control studies.

Case-control studies have the advantage of being relatively quick and inexpensive. They are limited in the sense that their results cannot be taken to show a cause-effect relationship, but they can strongly suggest it; hypothesized relationships can then be tested in prospective studies. Case-control studies are a useful design to begin exploring etiologies of conditions about which little is known, such as various soft tissue lesions, TMD, and other orofacial pain syndromes.

\section{Clinical Trials for Prevention and Treatment of Oral Diseases}

The randomized clinical trial is an experimental application of the epidemiological method, designed to test the hypothesis that a particular agent or regimen is efficacious in favorably altering the natural history of a disease. Probably the earliest example of a true clinical trial in dentistry, though it was not referred to as such at the time, was a study to test the efficacy of silver nitrate applications to prevent caries (Klein and Knutson, 1942). Numerous trials since then have tested various forms of fluoride for the prevention of caries, effects of educational approaches on oral hygiene behavior, the effectiveness of different treatments to control loss of attachment and bony support in periodontitis, and the efficacy of various mouthrinses to control plaque formation.

Most clinical trials in oral research have been for caries prevention in children, methods for which have now been developed to a high state of precision. Results of trials using randonized stratified allocation of children to test and control groups, double-blind designs, assessment of measurement error, and careful data analysis have no doubt contributed significantly to the caries decline. But with the caries decline in children, such trials will be seen less frequently in the future. Those that will be mounted will be in- creasingly confined to special groups of caries-susceptible children, which allows numbers of participants to be kept in bounds but diminishes the generalizability of results.

An increase can be expected in clinical trials for plaque-control mouthrinses for home use. Further development of drugs to control periodontitis is also likely, and clinical trials for such products will be required. These studies will need to be carefully designed because of the long-term nature of periodontitis. At present, such trials are difficult because of diag. nostic imprecision in periodontitis. With more precise diagnosis added to the constantly improving study designs, clinical trials for periodontitis treatments will become more frequent and more efficient. Trials for testing therapies for ulcers, herpes, and other softtissue lesions will likely become more frequent as well.

To date, dentistry has seen little development of clinical trials to assess the efficacy of different surgical, technical, and restorative treatments for oral diseases. Examples of evaluation trials that have been done are the studies to compare the efficacy of various methods of treating deep periodontal pockets and loss of attachment - studies which have substantially altered the approach to such treatment (Ramfjord et al., 1973; Knowles et al., 1979). Trials have also been conducted to test behavioral interventions to reduce fear and anxiety among dental patients (Ayer and Corah, 1984).

Broader application of these study philosophies and designs, however, would help rationalize many areas of dental treatment. There is ample need for trials to assess the efficacy of treatments for malocclusions and $\mathrm{TMD}$, both conditions upon which large amounts of money are being spent for untested therapies. Such studies will not be easy. In addition to considerable logistic difficulties, for example, randomization is more difficult than in caries prevention triais, and the problem of separating a true treatment effect from variation among providers will have to be dealt with.

\section{Personnel Needs}

Epidemiology is a complex science that requires specialized training, just as do other areas of oral research. Training should include advanced coursework in statistics, epidemiology, research design, and computer applications; courses as necessary in pathology, microbiology, immunology, genetics, environmental health, sociology, psychology, and economics; a thorough understanding of past developments in epidemiology, and sufficient understanding of research in other fields to facilitate multidisciplinary studies. Graduates of specialized training programs should be employed in Federal agencies like NIDR, NCHS, CDC, and the National Center for Health Services Research. Others are needed in dental schools, and in state and local health departments. Research advances will be slow without a "critical mass" of trained oral epidemiologists. 

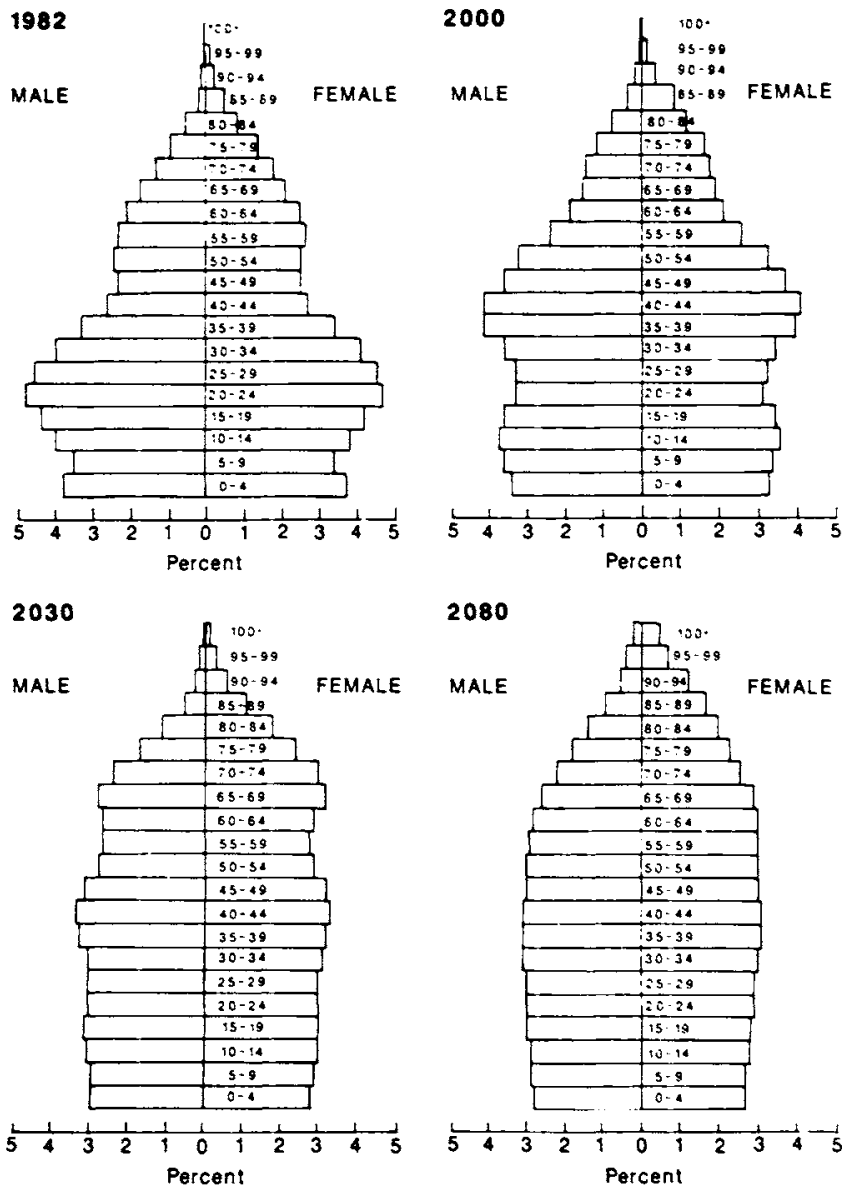

Fig. 2-Age and gender structure of the United States, 1982-2080. Source: U.S. Department of Commerce, 1984.

\section{TECHNICAL AND SOCIAL CHANGE}

There are two areas where changes will affect the practice of epidemiological research across the board. One is advances in computer technology, the other is the demographic shift in the age-structure of American society.

\section{Computers}

The availability of computers means that projects can now be conceived and carried out which would previously have been impossible; the range of variables collected in a study can be increased greatly, while the capacity to analyze them has already expanded. As the speed, power, and storage capacity of computers continue to grow, so more ambitious projects with complicated data analysis can be mounted. Computers permit the recording and analysis of the total range of genetic, physical, social, and psychosocial risk factors associated with the conditions under study. The capacity to collate and analyze many of these factors has probably exceeded our ability to measure them validly and reliably.
The need for oral epidemiological research to make better use of databases has already been discussed; even now, there are questions which could probably be answered more efficiently by analyzing existing data rather than by mounting new studies. To increase the number of databases, records from virtually all studies involving original data collection, when initial analysis is completed, should be routinely stored in computer banks for general analytic use. Ways to make databases from dental insurance groups more available to researchers would also release a data source of potentially high value in health services research. A central agency-such as CDC, NIDR, or the National Technical Information Service-could store and publicize these databases, and computer networks would make them readily accessible to researchers.

For those studies in which original data collection is required, direct data entry into computers rather than on a paper record has already been employed in field examinations (Eklund et al., 1987), and the newer portable computers are making this approach even more convenient. Field computers allow for a great savings in time between data collection and analysis, and errors are reduced at data entry. Where standard protocols can be used, software for analysis can also be employed by the researcher in the field, thus greatly facilitating the process of data analysis. The development of a system of oral disease surveillance, discussed earlier, would largely depend on the use of computerized data-entry systems and simple analysis packages to be successful.

\section{Demographic Change}

The "graying of America", the dimensions of which for the next 100 years are illustrated in Fig. 2, has raised a host of social and public policy issues that will not be resolved easily. The principal impact is that older persons will continue to make up an increasing proportion of the population. Their absolute numbers will also expand rapidly as the U.S. population grows to over 300 million (US Department of Commerce, 1984). They will also be living longer, and retaining more teeth (Weintraub and Burt, 1985). These facts have raised many research questions about the nature of the aging process, its sociology and psychology as they relate to oral diseases, and the oral disease conditions usually associated with age.

Disease trends can be interpreted more easily when society is separated into its various age-cohorts, for the various life experiences of the generations have influenced many factors differently, oral status included. For example, it cannot be taken from the current caries decline in children that coronal caries has necessarily been prevented permanently; it is possible that the carious attack may just be postponed until later in life. If this is occurring, the impact on the practice of dentistry will be profound. Even with the present older age-cohorts, there is some evidence that caries experience is increasing, and service demands 
are highly likely to increase (Douglass and Gammon, 1984). There has been some epidemiological study among older age-groups, both descriptive (Beck et al., 1984, 1985; Hand and Whitehill, 1986) and analytical (Douglass et al., 1983; Burt et al., 1985), but the oral health of older persons still requires further study. Root caries is associated with gingival recession ( $\mathrm{Ny}$ vad and Fejerskov, 1982; Burt et al., 1986), and gingival recession is more prevalent among dentate older persons, so aging of societv and greater tooth retention can be expected to increase the size of the root caries problem. While periodontitis may not be a natural consequence of aging for most persons up to age 74 (Page, 1984; Abdellatif and Burt, 1987), it is possible that diminished resistance becomes a factor in later years. These and related issues will require further research if the oral health of older persons is to be optimized.

\section{FRONTIERS FOR RESEARCH}

Epidemiology is an applied science; its theoretical basis and its methods are of little interest to anyone outside the field. It is only in its applications that it takes on form: the epidemiology of periodontal diseases, of oral cancer, and so on. Epidemiology is not as equipment-dependent as the laboratory sciences, so developments in areas like cell biology, which will transform laboratory and clinical research over the next 30 years, will affect epidemiology principally in the hypotheses tested and the diagnostic methods used. Today's diagnostic methods, based largely on clinical observation, will give way to more objective tests for the presence of diseases or their determinants.

To illustrate the impact of new technology on oral epidemiology, we have selected four research areas which will become more important with the aging of American society, and in which diagnostic imprecision has impeded research:

a. Periodontitis: Probably the major oral disease in terms of research interest for the immediate future. While caries has waned as a public health problem in American children, the nature of the disease process in periodontitis has been the subject of vigorous debate in recent years. The concept of site selectivity (Haffajee et al., 1982), the "burst" hypothesis for progression of lesions (Socransky et al., 1984), the increasing acceptance that periodontitis and gingivitis are distinct diseases (Polson and Goodson, 1985), and recent evidence suggesting a relatively low prevalence of generalized periodontitis (U.S. Public Health Service, 1987)-all have provoked spirited discussion. While many earlier beliefs are now strongly questioned, the fact remains that periodontitis has a major impact upon the oral health of millions of people, and will continue to do so for some time.

b. TMD and other orofacial pain: The extent and distribution of chronic pain in the facial area, with the exception of TMD to some extent, are almost completely unknown. Differentiation of some syndromes from TMD is often difficult. It is obvious to clinicians that chronic orofacial pain is a nightmare for the unfortunate persons who suffer from it, and methods of treatment are acknowledged to be inadequate. Systematic study has been extremely difficult in the past because of the problems with measuring pain, compounded by the problem of assessing the impact of behavioral and personality factors.

Even the epidemiology of TMD is poorly understood, as is the efficacy of the various methods devised to treat them. Patients appear to be predominantly white females aged 20-40, but it is not clear whether this is the group principally affected or whether they just constitute the main group of patients. In the meantime, large sums of money are being expended by the public on TMD treatment. TMD is not uncommon, and many think that its occurrence is increasing. The absence of a scientific basis for the study of TMD stems largely from the absence of a case-definition, the frequently diffuse nature of symptoms, uncertainty about the importance of clinical signs (such as clicks, occlusal sliding, and limitations of mandibular movement), and how these signs relate to personality and behavioral profiles.

c. Salivary gland dysfunction: It has already been stated that these conditions could be a factor in what appears to be a greater degree of coronal caries among older persons than previously imagined (Beck et al., 1985). Research on the effects of destruction of the salivary glands, usually from radiation therapy for cancer of the head and neck, has shown how the now-xerostomic patient is highly susceptible to caries. But subtler forms of salivary dysfunction probably occur, perhaps as a natural consequence of aging, possibly from drugs commonly used in old age (Fox et al., 1985), and possibly from other pathological causes. The impact of salivary gland dysfunction on caries has been principally assessed from the quantitative aspect of saliva flow (Abelson and Mandel, 1981) rather than from qualitative aspects. So far, there is little knowledge of how salivary gland dysfunctions influence periodontal diseases. Even the detection of these conditions has been hindered by diagnostic difficulties; crude measurements of salivary flow rates are frequently all that has been accomplished in clinical studies.

d. Health services research: The provision of health services was described earlier as a subsection of the social environment. Health services research, defined as "the inquiry to produce knowledge about the structure, processes, or effects of personal health services" (Institute of Medicine, 1979), has been included as a "frontier" condition because of the importance of linking epidemiological findings to the factors influencing receipt of dental care. Health services research also illustrates the breadth of application of the epidemiological method. The emergence of clinical epidemiological study in dentistry, espe- 
cially its application in clinical decision analysis (Douglass and McNeil, 1983), is probably the most direct merging of epidemiological science with clinical dentistry.

Health services research in dentistry has been applied to a breadth of issues pertinent to understanding the organization, financing, and delivery of dental care. Areas of research focus have included studies on the utilization of dental services, quality of dental care, measurements of the need for treatment, access to dental care, special population groups, and the assessment of oral health status. The epidemiological method can be applied to studies on care delivery, whereby groups of people who receive different exposures to various arrangements for receipt of dental care can be compared. Outcomes in such studies can be expressed in terms of both oral health status and social/behavioral aspects, such as frequency of use of services and satisfaction with care received.

There are two outstanding examples of large-scale studies of this type. One is the first International Collaborative Study, coordinated by the World Health Organization, which related the impact of the oral health care delivery system to the oral health status of recipients in ten nations (Arnljot et al., 1985). The other is the Rand Health Insurance Experiment, which allocated families in different geographic locations in the United States to several health care financing plans and followed their use of service and health outcomes over five years (Manning et al., 1985).

Each of these areas will be looked at in turn to assess what impact various new technological developments might have in the immediate future, the intermediate future, and in the long term.

\section{a. Periodontitis}

Short-term developments: Diagnosis of periodontitis is now based on clinical and radiographic assessment of gingival inflammation, probing pocket depth, and clinical loss of attachment. Diagnosis will continue to be clinically based for the immediate future-indeed, there will probably always be aspects of clinical assessment. But some new technologies will reduce the art of measurement in the gingival crevice and increase the science.

Periodontal probes in which the probing pressure can be electronically monitored assist in standardizing probing forces (Polson et al., 1980). Used in clinical studies, this computerized probe has not yet been proven for field studies. Another computerized periodontal probe which aids in detecting the cementoenamel junction (Jeffcoat et al., 1986) is still developmental, but if it reaches the point where it can be employed in the field, it could substantially reduce the problems associated with measurement validity and reliability. Cost and portability are probably the main determinants of its future practicality. Other diagnostic measures for which the technology already exists may join precision-probing in certain periodontal studies. For example, measures of gingival crevi- cular flow are already useful, and instruments which could measure certain constituents of crevicular flow as well as its quantity may prove to be even more diagnostically useful.

Intermediate-term developments: Diagnosis of periodontal conditions will move more to biologic measurements of disease indicators to complement clinical assessment. Technology exists at present for identification of periodontopathic bacteria by in-office antibody screening, and enzyme activity, but it is likely to be some years before these methods become standard in field studies. Indeed, it is not yet certain that all will fulfill their initial promise.

DNA probing, which is in limited use now, involves identification of bacteria by reading the genetic code, thus potentially allowing for a higher degree of reliability in bacterial identification than currently exists. At present, DNA probing identifies only the presence or absence of a limited number of species, but the number of species capable of being identified should grow quickly. One particular benefit of DNA probing and immunologic tests for future epidemiological studies is that they can be carried out with dead bacteria, whereas cultivation methods require live bacteria.

Advances in nuclear medicine have been applied only experimentally in periodontal research to date (Jeffcoat et al., 1985), but by this time may have become more commonplace diagnostic aids for determining bone loss. The method tested in beagle dogs uses an intravenous injection of a trace of diphosphonate compound labeled with the radionuclide $99 \mathrm{~m}$ technetium. The short half-life ( $6 \mathrm{hr})$ and gamma energy level are ideal for imaging bone; the material detects the metabolic change that precedes architectural change in bone.

The development of a technique for producing human monoclonal antibodies in the test tube (Casali et al., 1986) can be expected to lead to improved methods of diagnosis for a variety of conditions. The complexity and expense of monoclonal antibody techniques, however, make their future in epidemiological studies uncertain. Bacterial identification by enzyme activity appears to be a reasonable-cost technique; initial tests suggest that the ability of subgingival plaque to hydrolyze N-benzoyl-DL-arginine-2-naphthylamide (BANA) is a reliable marker for the presence of high proportions of spirochetes in the plaque sample (Loesche et al., 1987). Further tests of this approach in epidemiological studies are planned.

Long-term developments: In the future, it can be expected that diagnosis of periodontal susceptibility and active disease will be carried out almost entirely by extra-oral tests using bacterial, immunological, nuclear, or genetic markers, and that these tests will be relatively simple and inexpensive. This will make epidemiological studies much simpler and more directly useful, and could also permit early identification of periodontitis-susceptible individuals. By this 
time, it is likely that periodontitis will be sufficiently well understood that it will no longer be considered a public health problem.

\section{b. TMD and Other Orofacial Pain}

Short-term developments: The major advances in the measurement of pain over the last decade have made it feasible to begin descriptive epidemiological research. These new methods can be subdivided into measures of the patient's verbal report, measures of behavior, and physiological measures. Until recently, verbal report measures were considered unreliable and fraught with subject and experimenter bias. They usually involved simple measures of pain threshold, pain tolerance, and the use of category scales to assess the magnitude of pain or pain relief. Recent research, however, has resulted in major improvements in pain scales that utilize cross-modality matching procedures, measures of pain discrimination, and the use of quantifiable pain descriptors. Adjectives that describe a component of the patient's pain experience, such as its intensity (i.e., mild, moderate, intense), have become reliable and objective measures when they are quantified by cross-modality matching to known sensory measures, such as line length or time duration (Gracely et al., 1978). In addition, the use of experimental pain stimuli produces suprathreshold ratings of the pain experience along different dimensions, such as intensity and unpleasantness. These responses can then be compared to the patients' reports of their clinical pain (Heft et al., 1980).

Behavioral measures of pain include simple reflex measures, such as the jaw opening reflex or leg flexion in response to noxious or painful stimuli. More complex behavior includes facial expressions or vocalizations. These kinds of behavior can be better quantified by means of TV taping and waveform analyzers of different sounds. TV monitoring has proved to be useful in assessing other types of motor behavior that might be altered when a patient is in pain.

Physiological measures that correlate with pain include levels of muscle activity from painful sites, autonomic nervous system activity, and electrophysiological records of nerve activity. The latter includes measures of the activity of populations of neurons (i.e., compound action potentials or EEG activity) and recordings of single-nerve action potentials from peripheral nerve fibers.

For research in the epidemiology of TMD, the most immediate need is a case-definition: specification of normal and abnormal joint movement to add to clinical and psychological measures. An NIDR-sponsored workshop in October, 1984 (proceedings not published), proposed that a case-definition be based on (a) subjective pain, (b) clinically-determined pain from tenderness on palpation of the joint or associated muscles, and (c) dysfunction assessed by limitation of movement or joint sounds.

In addition to the advances in measuring pain just described, technological developments in tomography, arthrography, pressure algometry, and magnetic resonance imaging may assist in future TMD studies, though their application to epidemiology will not be automatic because of high cost and ethical considerations. Computerized tomography involves multiple radiographic exposures from different angles. These multiple images are then combined with computer assistance to provide three-dimensional images. This potentially powerful diagnostic technique is clearly expensive, and the degree of exposure to radiation it entails presents ethical difficulties in epidemiological studies. Arthrography requires injection of a radio-opaque dye into the joint prior to radiography, sometimes with tissue reaction to the dye. It is also considered a technically demanding procedure. The pressure algometer has been shown to be reliable in measuring myofascial trigger-point sensitivity (Reeves et al., 1986). While the necessity of adhering to strict methodological guidelines has been demonstrated (Fricton and Schiffman, 1987), algometry appears to be a promising approach in TMD study. Magnetic resonance (MR) imaging - in which the patient is physically placed in an MR scanner to act as an external magnetic field, and the images are transmitted by radio frequency waves - has several advantages over computerized tomography and arthrography. It provides soft-tissue contrast that the others do not, it is non-invasive, and it does not subject the patient to ionizing radiation. The technique has already been tried in a small study of symptomatic and asymptomatic patients, with encouraging results (Manzione et al., 1986). The drawback is that the procedure is extremely expensive and requires a sophisticated institutional base.

Intermediate-term developments: Over time, the above pain assessment methods will be combined with measures of various metabolites that are associated with the onset of clinical pain. For example, the stress of oral surgical procedures leads to a release of opioid peptides from the pituitary and monoamines from the adrenal medulla. The levels of opioid peptides in plasma and cerebrospinal fluid are closely related to patient pain reports following oral surgery. Drug manipulations that alter pain levels also alter levels of these opioid peptides (Hargreaves et al., 1986). The peripheral inflammatory process is also associated with the release of various neuropeptides into the tissue fluid, and the levels of some of these compounds also appear to be related to patient reports of pain. The fact that they correlate well with verbal report assays of pain will lead to improved and highly objective methods for measuring pain before and after various treatments. Epidemiological studies in the intermediate future will be able to make increasing use of these new biochemical assays as measures of clinical pain.

For TMD studies, magnetic resonance imaging may become more available and less expensive. In its present form, it is not a portable item of field equip- 
ment, but developments on the MR principle may reach the point where it will become much simpler. What seems unlikely to change, however, are the ethical constraints on use of radiographic and arthrographic techniques for non-symptomatic persons.

It can also be expected by this time that behavioral and personality measurement, an important aspect of TMD diagnosis in many cases, will be advanced beyond current procedures. Analytical studies to seek etiology of TMD are likely to be mounted when all the physical, biological, and psychological factors likely to be involved can be measured with precision.

Long-term developments: With a growing variety of descriptive and analytical studies, together with other basic and clinical research on orofacial pain, it can be expected that in the long term these conditions will be controlled. Although recent research has revealed that the brain has its own pain-suppressing systems, these systems cannot be activated under normal physiological conditions. These pathways are associated with a host of neurochemicals such as different opioid peptides, monoamines such as serotonin and norepinephrine, and many recently discovered neuropeptides. The future development of new approaches to activating these systems will result in methods by which people can control their own pain. In addition, the release of neurochemical markers associated with activation of these pain-suppressing systems will provide additional objective assays of pain and its magnitude.

Non-invasive, multi-dimensional imaging techniques will most likely have reached the point where capturing TMD images for diagnosis is no more arduous than exposing a dental $x$-ray film is today. Epidemiological diagnosis will be simple enough that cohort studies and clinical trials to test treatment methods could be conducted without special concerns. These and related studies will produce methods for determining the susceptibility of individuals to TMD and permit preventive measures to be instituted. Treatment and preventive methods will be evaluated through clinical trials.

\section{c. Salivary Gland Dysfunction}

Short-term developments: Recent research has greatly expanded knowledge of how saliva formation takes place, and has raised diagnostic consciousness to the possibility of subtle salivary disorders which at present defy definitive diagnosis. Several ion channels and carrier-mediated transporters for transepithelial cell water movement are now recognized, and most neurotransmitter receptor control mechanisms involved have been identified. Current research for diagnosis of gland dysfunction is based on experimental imaging methods and use of isotopic probes. At present, none of these mechanisms has advanced to the stage of clinical applications.

Intermediate-term developments: The techniques described are likely to have reached the point of direct clinical applications, but may still be expensive and impractical for field use. Epidemiological research at this time may be focused on determination of the roles played by particular constituents of saliva, and so would require precise identification of these constituents from groups of subjects with and without particular clinical syndromes. When molecular and immunological probes reach the point of practical and relatively inexpensive use, then classic epidemiological studies can be mounted.

One practical result of an ability to diagnose various degrees of salivary dysfunction would be to relate these conditions to various medical and social factors. As one example, some xerostomic drugs are already known. As more such drugs, and drug combinations, become identified through the results of such studies, health practitioners could have ready access to this information through computer banks to assist their treatment of patients.

Long-term developments: The development of highly specific diagnostic probes may reach the point where initial diagnosis can be carried out at home with a kit from the local drug store. Screening examinations, such as for elderly persons in the highrisk group for xerostomia (bearing in mind that "the elderly" in 40 years' time will be older than today's elderly), might be carried out with simple tests in nursing homes or in the patient's home. A degree of diagnostic precision will allow subtle dysfunctions of salivary glands to be readily identified.

\section{d. Health Services Research}

Short-term developments: Health services research as an applied field has relied upon systematic analysis of complex data sets, use of empirical methods, arid collaborative efforts of dental researchers with other disciplines. It relies on descriptive and analytical studies to explore research questions that ultimately affect the formulation and implementation of dental health policy. For the immediate future, health services researchers will continue to address issues that emanate from the upward spiral of dental care costs, questions about the financing of dental care, the maldistribution of services, and the need for professional consensus as to the quality and appropriateness of dental care.

More research will be carried out in the area of quality assessment, especially of high-cost services like implants and TMD surgery. Current methods to evaluate structure, process, and outcome of dental care will be refined, and additional quality assessment tools will be developed. For example, validation studies will be performed to compare indirect review of dental records with direct assessment via clinical examination of patients. Reliable and valid quality assessment methods will be used to evaluate alternative delivery systems and the various mechanisms available to finance dental care; studies to evaluate the effect of payment source on costs, quality of care, health status, and behavior will become more commonplace. Other studies will assess the impact of 
business practices, advertising, and use of paraprofessional providers on the quality of care, and the ability of state agencies to influence quality.

With limited resources, more short-term emphasis will be placed on studies that focus on the relationship between the allocation of dental care resources and oral health status. Purchasers of dental care, including large corporations and the Federal Government, will be looking for ways to maximize benefits for dollars spent. In response to this need, there will be an increase in the development of research protocols in cost-effectiveness and cost-benefit analysis. Also, more studies evaluating the dental health problems of target populations to determine costs and quality of care will emerge.

There will also be further emergence of clinical epidemiology (Sackett et al., 1985) in dental research, especially the use of decision analysis. With more empirical data on treatment outcomes, decision analysis will be employed more as a systematic approach to determining appropriate treatment (Douglass and McNeil, 1983).

Intermediate-term developments: More studies will focus on the relationship between process and outcome of dental care. Researchers will determine the most cost-effective therapies by systematically studying factors such as length of treatment, retention of various restorations, and the negative effects of these therapies. By development of norms of care and expected dental outcomes, it will be possible for undertreatment, overtreatment, unnecessary treatment, and mistreatment to be identified. It will also be possible to develop indices of therapeutic need that will be used to translate existing conditions into appropriate treatment interventions.

The impact of the aging population on the dental delivery system will be studied extensively as we approach and enter the 21 st century. Health services researchers will examine the consumption of dental services by the elderly in terms of expenditures and demands on the dental care system. For example, there will be increased research on what the aged can expect from the dental care system as the elderly incur greater out-of-pocket costs and as benefits and eligibility for care are reduced.

Clinical epidemiology by this time is likely to have made decision analysis a regular part of the dental school curriculum. Other research will focus on the financing of dental care and the effects of reimbursement changes on cost, access, and quality of care. As changes occur in Federal, state, and private sector reimbursement policies, alternative ways of reimbursing dental providers will be studied, and reimbursement incentives to promote alternative ways of delivering dental care will be evaluated.

Long-term developments: State, regional, and national data banks will pool useful information provided by governmental agencies, purchasers of care in the private sector, fiscal intermediaries, and individual dental practices. Health services researchers will thus have immediate access to on-line data, including utilization rates, service mix, and costs, for every conceivable combination of providers, population groups, and payment sources. Analysis of this information will be used to influence decisions of providers and payers and to improve understanding of the functioning of the dental delivery system. For example, by examination of differences and similarities in dental practice patterns, it will be possible for consensus on standards of care for general and specialty practice to be developed.

There will be movement toward adopting more experimental designs in lieu of survey methods in conducting health services research. Cause-and-effect relationships between variables will thus be developed by the assigning of subjects to alternative treatment interventions and control groups. For example, it will be possible to determine the efficacy of various quality assurance systems by randomly assigning dental practices within a capitation or fee-for-service network to alternative interventions. The ability of different systems to detect and correct quality of care deficiencies will then be assessed.

\section{REFERENCES}

ABDELLATIF, H.M. and BURT, B.A. (1987): An Epidemiological Investigation into the Relative Importance of Age and Oral Hygiene Status as Determinants of Periodontitis, I Dent Res 66:1318.

ABELSON, D.C. and MANDEL, I.D. (1981): The Effect of Saliva on Plaque $\mathrm{pH}$ in vivo, J Dent Res 60:1634-1638.

ARNLJOT, H.A.; BARMES, D.E.; COHEN, L.K.; HUNTER, P.B.V.; and SHIP, I.I. (1985); Oral Health Care Systems: An International Collaborative Study. London: Quintessence and World Health Organization.

ARNOLD, F.A., Jr.; LIKINS, R.C.; RUSSELL, A.L.; and SCOTT, D.B. (1962): Fifteenth Year of the Grand Rapids Fluoridation Study, I Am Dent Assoc 65:780-785.

AST, D.B. and FITZGERALD, B. (1962): Effectiveness of Water Fluoridation, ] Am Dent Assoc 65:581-588.

AYER, W.A. and CORAH, N.L. (1984): Behavioral Factors Influencing Dental Treatment. In: Social Sciences and Dentistry, Volume II, L.K. Cohen and P.S. Bryant, Eds., London: Quintessence and Federation Dentaire Internationale, pp. 267-322.

BACKER DIRKS, O.; HOUWINK, B.; and KWANT, G.W. (1961): The Results of 6-1/2 Years of Artificial Fluoridation of Drinking Water in The Netherlands; the Tiel-Culemborg Experiment, Arch Oral Biol 5:284-300

BECK, I.D.; CONS, N.C.; FIELD, H.M.; and WALKER, I. (1982): The Iowa Survey of Oral Health: 1980, lowa City, IA: The Unjversity of lowa.

BECK, J.; HUNT, R.J.; HAND, J.S.; and FIELD, H.M. (1985): Prevalence of Root and Coronal Caries in a Noninstitutionalized Older Population, / Am Dent Assoc 111:964-967.

BECK, J.D.; LAINSON, P.A.; FIELD, H.M.; and HAWKINS, B.F. (1984): Risk Factors for Various Levels of Periodontal Disease and Treatment Needs of Iowa, Community Dent Oral Epidemiol 12:17-22.

BLACK, G.V. and McKAY, F.S. (1916): Mottled Teeth-an Endemic Developmental Imperfection of the Teeth Heretofore Unknown in the Literature of Dentistry, Dent Cosmos 58:129-156. 
BLAYNEY, J.R. and HILL, I.N. (1967): Fluorine and Dental Caries, J Am Dent Assoc 74 (Sp Iss):233-302.

BRESLOW, L. (1980): Cigarette Smoking and Heaith, Pub Health Rep 95:451-455.

BURT, B.A. (1978): Influences for Change in the Dental Health Status of Populations; an Historical Perspective, I Public Health Dent 38:272-288.

BURT, B.A.; ISMAIL, A.I.; and EKLUND, S.A. (1985): Periodontal Disease, Tooth Loss, and Oral Hygiene Among Older Americans, Community Dent Oral Epidemiol 13:93-96.

BURT, B.A.; ISMAIL, A.I.; and EKLUND, S.A. (1986): Root Caries in an Optimally Fluoridated and a High-fluoride Community, $J$ Dent Res 65:1154-1158.

CASALI, P.; INGHIRAMI, G.; NAKAMURA, M.; DAVIES, T.F.; and NOTKINS, A.L. (1986): Human Monoclonals from Antigenspecific Selection of $B$ Lymphocytes and Transformation by EBV, Science 234:476-479.

CHEN, M.K. and LOWENSTEIN, F. (1984): Masticatory Handicap, Socioeconomic Status, and Chronic Conditions Among Adults, J Am Dent Assoc 109:916-918.

DEAN, H.T.; ARNOLD, F.A., Jr.; and ELVOVE, E. (1942): Domestic Water and Dental Caries. V. Additional Studies of the Relation of Fluoride Domestic Waters to Dental Caries Experience in 4,425 White Children, Aged 12 to 14 Years, of 13 Cities in 4 States, Pub Health Rep 57:1155-1179.

DEAN, H.T.; JAY, P.; ARNOLD, F.A., Jr.; and ELVOVE, E. (1941): Domestic Water and Dental Caries. II. A Study of 2,832 White Children, Aged 12 to 14 Years, of 8 Suburban Chicago Communities, including Lactobacillus acidophilus Studies of 1,761 Children, Pub Health Rep 56:761-792.

DePAOLA, P.F.; SOPARKAR, P.; FOLEY, S.; BOOKSTEIN, F.; and BAKHOS, Y. (1977): Effect of High-concentration Ammonium and Sodium Fluoride Rinses in Dental Caries in Schoolchildren, Community Dent Oral Epidemiol 5:7-14.

DOLL, R. and BRADFORD HILL, A. (1956): Lung Cancer and Other Causes of Death in Relation to Smoking; a Second Report on the Mortality of British Doctors, Br Med J 2:1071-1081.

DOLL, R. and BRADFORD HILL, A. (1964): Mortality in Relation to Smoking: Ten Years' Observations on British Doctors, $\mathrm{Br}$ Med J 1:1399-1410, 1460-1467.

DOUGLASS, C.W. and GAMMON, M.D. (1984): The Epidemiology of Dental Caries and its Impact on the Operative Dentistry Curriculum, J Dent Ed 48:547-555.

DOUGLASS, C.W. and McNEIL, B. (1983): Clinical Decision Analysis Methods Applied to Diagnostic Tests in Dentistry, ] Dent Ed 47:708-712.

DOUGLASS, C.W.; GILLINGS, D.; SOLLECITO, W.; and GAMMON, M. (1983): National Trends in the Prevalence and Severity of the Periodontal Diseases, J Am Dent Assoc 107:403-412.

EKLUND, S.A.; BURT, B.A.; ISMAIL, A.I.; and CALDERONE, J.J. (1987): High Fluoride Drinking Water, Fluorosis, and Dental Caries in Adults, I Am Dent Assoc 114:324-328.

FRICTON, J.R. and SCHIFFMAN, E.L. (1987): The Craniomandibular Index: Validity, $J$ Prosthet Dent 58:222-228.

FOX, P.C.; van der VEN, P.F.; SONIES, B.C.; WEIFFENBACH, J.M.; and BAUM, B.J. (1985): Xerostomia: Evaluation of a Symptom with Increasing Significance, I Am Dent Assoc 110:519-525.

GLASS, R.L. and SHIERE, F.R. (1978): A Clinical Trial of a Calcium Carbonate Base Dentifrice Containing 0.76\% Sodium Monofluorophosphate, Caries Res 12:284-289.

GRACELY, R.J.; DUBNER, R.; MCGRATH, P.; and HEFT, M. (1978): New Methods of Pain Measurement and Their Application to Pain Control, Int Dent J 28:52-65.

GREENE, J.C. (1963): Oral Hygiene and Periodontal Disease, Am I Pub Health 53:913-922.
GREENE, J.C. (1967): The Oral Hygiene Index-Development and Uses, J Periodontol 38 (part II):625-635.

HAFFAJEE, A.M.; SOCRANSKY, S.S.; and GOODSON, J.M. (1982): Periodontal Disease Activity, I Periodont Res 17:521-522.

HAND, J.S. and WHITEHILL, J.M. (1986): The Prevalence of Oral Mucosal Lesions in an Elderly Population, J Am Dent Assoc 112:74-76.

HARGREAVES, K.M.; DIONNE, R.A.; MUELLER, G.P.; GOLDSTEIN, D.S.; and DUBNER, R. (1986): Naloxone, Fentanyl, and Diazepam Modify Plasma Beta-Endorphin Levels During Surgery, Clin Pharmacol Therap 40:165-171.

HEFT, M.W.; GRACELY, R.H.; DUBNER, R.; and McGRATH, P.A. (1980): A Validation Model for Verbal Descriptor Scaling of Human Clinical Pain, Pain 9:363-373.

HUGHES, J.T.; ROZIER, R.G.; and RAMSEY, D.L. (1982): Natural History of Dental Diseases in North Carolina 1976-1977, Durham, NC: Carolina Academic Press.

HUTTON, W.L.; LINSCOTT, B.W.; and WILLIAMS, D.B. (1956): Final Report of Local Studies on Water Fluoridation in Brantford, Can J Pub Health 47:89-92.

INSTITUTE OF MEDICINE (1979): Report of a Study on Health Services Research, No. 78-06, Washington, DC: National Academy of Sciences.

ISMAIL, A.I.; BURT, B.A.; and EKLUND, S.A. (1984): The Cariogenicity of Soft Drinks in the United States, J Am Dent Assoc 109:241-245.

JEFFCOAT, M.K.; JEFFCOAT, R.L.; JENS, S.C.; and CAPTAIN, K. (1986): A New Periodontal Probe with Automated CementoEnamel Junction Detection, J Clin Periodontol 13:276-280.

JEFFCOAT, M.K.; WILLIAMS, R.C.; KAPLAN, M.L.; and GOLDHABER, P. (1985): Bone-seeking Radiopharmaceutical Uptake as an Indicator of Active Alveolar Bone Loss in Untreated and Surgically Treated Teeth in Beagle Dogs, I Periodont Res 20:301-306.

KLEIN, H. and KNUTSON, J.W. (1942): Studies on Dental Caries. XIII. Effect of Ammoniacal Silver Nitrate on Caries in the First Permanent Molar, J Am Dent Assoc 29:1420-1426.

KNOWLES, J.W.; BURGETT, F.G.; NISSLE, R.R.; SCHICK, R.A.; MORRISON, E.C.; and RAMFJORD, S.P. (1979): Results of Periodontal Treatment Related to Pocket Depth and Attachment Level. Eight Years, J Periodontol 50:225-233.

KNUTSON, J.W. and ARMSTRONG, W.D. (1943): Effect of Topically Applied Sodium Fluoride on Dental Caries Experience, Pub Health Rep 58:1701-1715.

LAST, J.M., Ed. (1983): Dictionary of Epidemiology, New York: Oxford University Press.

LOESCHE, W.J.; SYED, S.A.; and STOLL, J. (1987): Trypsin-like Activity in Subgingival Plaque: a Diagnostic Marker for Spirochetes and Periodontal Disease?, J Periodontol 58:266-273.

MANNING, W.G.; BAILIT, H.L.; BENIAMIN, B.; and NEWHOUSE, J.P. (1985): The Demand for Dental Care: Evidence from a Randomized Trial in Health Insurance, J Am Dent Assoc 110:895-902.

MANZIONE, J.V.; KATZBERG, R.W.; TALLENTS, R.H.; BESSETTE, R.W.; SANCHEZ-WOODWORTH, R.E.; COHEN, B.D.; and MACHER, D. (1986): Magnetic Resonance Imaging of the Temporomandibular Joint, J Am Dent Assoc 113:398-402.

MORRIS, J.N. (1975): Uses of Epidemiology, 3rd ed., New York: Churchill Livingstone.

NYVAD, B. and FEJERSKOV, O. (1982): Root Surface Caries: Clinical, Histopathological and Microbiological Features and Clinical Implications, Int Dent J 32:311-326.

PAGE, R.C. (1984): Periodontal Diseases in the Elderly: A Critical Evaluation of Current Information, Gerodontol 3:63-70.

POLSON, A.M.; CATON, J.G.; YEAPLE, R.N.; and ZANDER, H. (1980): Histological Determination of Probe Tip Penetration into Gingival Sulcus of Humans Using an Electronic Pressure-sensitive Probe, $J$ Clin Periodontol 7:479-488. 
POLSON, A.M. and GOODSON, J.M. (1985): Periodontal Diagnosis: Current Status and Future Needs, / Periodontol 56:25-34.

RAMFJORD, S.P.; KNOWLES, J.W.; NISSLE, R.R.; SCHICK, R.A.; and BURGETT, F.G. (1973): Longitudinal Study of Periodontal Therapy, J Periodontol 44:66-77.

REEVES, J.L.; JAEGER, B.; and GRAFF-RADFORD, S.B. (1986): Reliability of the Pressure Algometer as a Measure of Myofascial Trigger Point Sensitivity, Pain 24:313-321.

RUGG-GUNN, A.J.; HOLLOWAY, P.J.; and DAVIES, T.G.H. (1973): Caries Prevention by Daily Fluoride Mouthrinsing, Br Dent $]$ 135:353-360.

RUSSELL, A.L. (1956): A System of Scoring for Prevalence Surveys of Periodontal Disease, J Dent Res 35:350-359.

RUSSELL, A.L. (1963): International Nutrition Surveys: A Summary of Preliminary Dental Findings, ] Dent Res 42:233-244.

RUSSELL, A.L. and AYERS, P. (1960): Periodontal Disease and Socioeconomic Status in Birmingham, Alabama, Am / Pub Health 50:206-214.

SACKETT, D.L.; HAYNES, R.B.; and TUGWELL, P. (1985): Clinical Epidemiology: a Basic Science for Clinical Medicine. Toronto: Little, Brown.

SCHLESSELMAN, J.J. (1982): Case-Control Studies: Design, Conduct, Analysis, New York: Oxford University Press.

SOCRANSKY, S.S.; HAFFAJEE, A.D.; GOODSON, J.M.; and LINDHE, J. (1984): New Concepts of Destructive Periodontal Disease, I Clin Periodontol 11:21-32.
SOUTH CAROLINA DEPARTMENT OF HEALTH AND ENVIRONMENTAL CONTROL (undated): The South Carolina Dental Health and Pediatric Blood Pressure Survey 1982-83, Columbia.

STRIFFLER, D.F.; YOUNG, W.O.; and BURT, B.A. (1983): Dentistry, Dental Practice, and the Community, Philadelphia: Saunders, pp. 156-160.

US DEPARTMENT OF COMMERCE, BUREAU OF THE CENSUS (1984): Projections of the Population of the United States, by Age, Sex, and Race 1983 to 2080. Series P-25, No. 952. Washington, DC: U.S. Government Printing Office.

US PUBLIC HEALTH SERVICE, CENTERS FOR DISEASE CONTROL (1975): The Health Consequences of Smoking, 1975, DHEW Publication No. (CDC) 76-8704. Washington, DC: U.S. Government Printing Office.

US PUBLIC HEALTH SERVICE, NATIONAL CENTER FOR HEALTH STATISTICS (1979): Basic Data on Dental Examination Findings of Persons 1-74 Years; United States, 1971-1974, DHEW Publication No. (PHS) 79-1662.

US PUBLIC HEALTH SERVICE, NATIONAL INSTITUTE OF DENTAL RESEARCH (1981): The Prevalence of Dental Caries in United States Children 1979-80, NIH Publication No. 82-2245.

US PUBLIC HEALTH SERVICE, NATIONAL INSTITUTE OF DENTAL RESEARCH (1987): Oral Health of United States Adults; National Findings, NIH Publication No. 87-2868.

WEINTRAUB, J.A. and BURT, B.A. (1985): Tooth Loss in the United States, I Dent Ed 49:368-376. 